\title{
Iron Deficiency Anemia in Infancy: Long-Lasting Effects on Auditory and Visual System Functioning
}

\author{
CECILIA ALGARÍN, PATRICIO PEIRANO, MARCELO GARRIDO, FELIPE PIZARRO, AND \\ BETSY LOZOFF
}

Laboratory of Sleep and Functional Neurobiology, INTA, University of Chile, Chile [C.A., P.P., M.G., F.P.]; Center for Human Growth and Development, University of Michigan, Ann Arbor, Michigan, U.S.A. [B.L.]

\begin{abstract}
ABST
Evoked potentials provide noninvasive measures of nerve
transmission and CNS functioning. Auditory brainstem re-
sponses (ABR) and visual evoked potentials (VEP) show dra-
matic changes in infancy, largely as a result of progressive
myelination. Because iron is required for normal myelination,
pathway transmission in these sensory systems might be affected
by early iron deficiency. We previously reported evidence to that
effect: infants with iron-deficiency anemia (IDA) had slower
transmission through the auditory brainstem pathway, uncor-
rected by iron therapy. To determine long-term effects, ABR
and/or VEP of healthy Chilean children who were treated for
IDA or were nonanemic in infancy were compared at approxi-
mately 4 y of age. Absolute latencies for all ABR waves and
interpeak latencies (except I-III interval) were significantly
longer in former IDA children. Longer latency was also observed
\end{abstract}
for the P100 wave on VEP. The magnitude of differences was large-about 1 SD. These findings, with differences in latencies but not amplitudes, further support the hypothesis that IDA in infancy alters myelination and provide evidence that effects on transmission through the auditory and visual systems can be long lasting. Subtle changes in sensory pathway transmission might be an underlying mechanism for the derailment of other developmental aspects in early IDA. (Pediatr Res 53: 217-223, 2003)

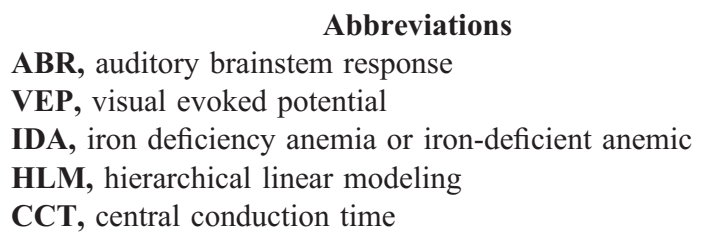

Neurophysiologic methodologies are noninvasive approaches that can provide information about the functional integration of the CNS. For example, dramatic decreases in latencies in auditory and visual evoked potentials in infancy are often used to index the overall intactness and maturation of the CNS. Progressively shorter latencies until adult levels are achieved are thought to reflect the increasing speed of transmission through sensory pathways, resulting in large part from increased myelination of the auditory and optic nerves and at the intracerebral level (1-5).

ABR represent the progressive activation of different levels of the auditory pathway: wave I is generated peripherally in the

Received December 5, 2001; accepted September 27, 2002.

Correspondence: Patricio Peirano, M.D., Ph.D., Sleep and Functional Neurobiology Laboratory, INTA, University of Chile, P.O. Box 138-11 Santiago, Chile; e-mail: ppeirano@uec.inta.uchile.cl

Supported by the National Institutes of Health, Bethesda, MD, U.S.A. (R01 HD33487 and T37 TW00035) and the Chilean Agency for Funding in Science and Technology (CONICYT, Fondecyt grant 1000657).

Preliminary results were presented at the Pediatric Academic Societies meetings, Ambulatory Pediatrics Plenary Session, Baltimore, MD, U.S.A., April 30, 2001.

DOI: 10.1203/01.PDR.0000047657.23156.55 auditory nerve, wave III reflects the firing of axons exiting the cochlear nuclear complex, and wave $\mathrm{V}$ reflects an action potential generated by axons from the lateral lemniscus $(6,7)$. We recently reported the use of $A B R$ to determine the effects of early IDA on the functional development of the auditory system (8). Six-month-old Chilean infants with IDA tended to show longer latencies than controls, indicating slower transmission through the brainstem portion of the auditory pathway. Differences became pronounced at 12 and $18 \mathrm{mo}$, despite iron therapy. Because iron is required for the functioning of several neurotransmission systems, myelination, and neuronal metabolic activity, different processes may relate to these lasting ABR abnormalities. However, the findings of differences in latency but not amplitude and more effects on the central (versus peripheral) portion of the auditory pathway appeared to be strong support for the hypothesis that impaired myelination was the explanation for the findings (8). This interpretation relied on basic research showing that a) iron is intimately involved in oligodendrocyte function and the associated production and maintenance of myelin $(9-12)$; and b) the rapid decrease in ABR latencies in infancy is primarily caused by myelination (13-15). 
The framework of impaired myelination also led us to postulate that other systems that are rapidly myelinating in infancy would be affected by early IDA. The visual system is particularly interesting in this respect, as it also matures dramatically in infancy. VEP represent the brain's electrical activity for a defined time after a visual stimulus. The decrease in latency of the major VEP component (wave P100) in early childhood is a well-recognized indicator of functional maturation of the visual pathway, primarily involving myelination of the optic nerve (5) but also multiple synapses at other levels between the retina and the primary visual cortex. More precisely, the generation of wave P100 localizes in the lateral extrastriate cortex (area 18), with corresponding activations in areas V3, V3a, and adjacent middle occipital gyrus (16).

We report here a study of ABR and VEP in former IDA children and controls at approximately 4 y of age. Because ABR differences had still been apparent after a year of oral iron in infancy, it was unclear whether differences would persist or resolve over the next several years. Our observation that differences remained after an entire year raised the possibilities of permanent changes or delayed maturation. We expected that the visual system would also have been affected in infancy but had no basis for specific predictions about long-term effects.

\section{METHODS}

Subjects. The children in this follow-up study had participated in previous research in Chile on the behavioral, developmental, and neurofunctional effects of IDA in infancy in the context of a randomized controlled trial of preventing IDA. Detailed descriptions of the population and findings during infancy have been published elsewhere $(8,17)$. In brief, study participants were healthy full-term infants (birth weights $\geq 3.0$ $\mathrm{kg}$, no perinatal complications, and no acute or chronic illnesses). Infants were identified as having IDA at 6,12 , or 18 mo. Anemia was defined as venous $\mathrm{Hb} \leq 100 \mathrm{~g} / \mathrm{L}$ at 6 mo and $<110$ $\mathrm{g} / \mathrm{L}$ at 12 and $18 \mathrm{mo}$. Iron deficiency was defined as two of three iron measures in the iron-deficient range [mean cell volume $<70 \mathrm{fL}$, erythrocyte protoporphyrin $>100 \mu \mathrm{g} / \mathrm{dL}$ red blood cells $(1.77 \mu \mathrm{M})$, serum ferritin $<12 \mu \mathrm{g} / \mathrm{L})$ and/or an increase in $\mathrm{Hb} \geq 10 \mathrm{~g} / \mathrm{L}$ after 6 mo of iron therapy (18). These cutoffs for anemia and iron measures were based on the consensus of the hematologists of the project (T. Walter) and its External Advisory Committee (P. Dallman, F. Viteri, and R. Yip), who used normative data to determine approximately 2 SD from the mean for age (19-21). For each IDA infant, the next infant of the same age who was clearly nonanemic (venous $\mathrm{Hb} \geq 115 \mathrm{~g} / \mathrm{L}$ ) was invited to join the study as part of the "control" group. Six-month-old infants were treated for 1 y with $15 \mathrm{mg} / \mathrm{d}$ of elemental iron as oral ferrous sulfate; infants identified at 12 or 18 mo were treated with oral iron $(30 \mathrm{mg} / \mathrm{d})$ for a minimum of 6 mo. Infants from the control group were also treated with iron to assure that they did not become iron deficient with advancing age in this setting where iron deficiency was widespread.

Between 1997 and 2000, evoked potential studies (ABR and VEP) were conducted for study children at preschool age. Of the available children who had been part of the earlier study (6,
12 , and 18 mo IDA and control groups), we choose those who were still under $5 \mathrm{y}$ of age. Overall, $11 \%$ declined further participation and $16 \%$ could not be located or had moved outside the region. ABR and VEP data were obtained from participating children. A total of $64 \mathrm{ABR}$ and 80 VEP recordings of good quality, collected at average ages of $4.3 \mathrm{y}$ and $4.0 \mathrm{y}$, respectively, were available for analysis. In all, 41 former IDA children and 43 controls had usable data. The research protocols in infancy and at follow-up were approved by the institutional review boards of the University of Michigan Medical Center, Ann Arbor, of INTA, University of Chile, Santiago, and of the Office of Protection from Research Risks, National Institutes of Health. Signed informed consent was obtained for each phase of the study.

The characteristics of children with ABR and/or VEP data in this follow-up are presented in Table 1. Former IDA children tended to be male, weigh slightly less at birth with a bit shorter gestation (even at term, with birth weights of $3.0 \mathrm{~kg}$ or more), and gain more weight between birth and 6 mo. Therefore, these factors were controlled for in analyses of evoked potentials. Weight gain between birth and 6 mo showed no statistically

Table 1. Background characteristics*

\begin{tabular}{|c|c|c|}
\hline Group & Former IDA & Control \\
\hline & $(n=41)$ & $(n=43)$ \\
\hline Age at ABR (y) & $4.26 \pm 0.10$ & $4.32 \pm 0.08$ \\
\hline No. & 29 & 35 \\
\hline Age at VEP (y) & $3.89 \pm 0.09$ & $4.03 \pm 0.08$ \\
\hline No. & 40 & 40 \\
\hline Gender $(\%$ male $) \dagger$ & 63.4 & 44.2 \\
\hline \multicolumn{3}{|l|}{ Characteristics in infancy } \\
\hline Birth weight $\dagger$ & $3429 \pm 59$ & $3582 \pm 67$ \\
\hline Gestational age $\dagger$ & $39.2 \pm 0.2$ & $39.6 \pm 0.2$ \\
\hline \multicolumn{3}{|l|}{ Growth at $6 \mathrm{mo}$} \\
\hline Weight for age (z-score) & $0.57 \pm 0.14$ & $0.44 \pm 0.11$ \\
\hline Length for age (z-score) & $-0.17 \pm 0.15$ & $0.05 \pm 0.13$ \\
\hline $\begin{array}{l}\text { Weight gain, birth to } 6 \\
\text { mot }\end{array}$ & $4765 \pm 112$ & $4408 \pm 102$ \\
\hline \multicolumn{3}{|l|}{ Iron measures in infancy§ } \\
\hline IDA detected at 6 mo, no. & 10 & 10 \\
\hline Hemoglobin $(\mathrm{g} / \mathrm{L})$ & $94.5 \pm 1.6$ & $124.3 \pm 1.7$ \\
\hline $\begin{array}{l}\text { Erythrocyte protoporphyrin } \\
(\mu \mathrm{g} / \mathrm{dL} \mathrm{RBC})\end{array}$ & $201.6 \pm 30.5$ & $85.1 \pm 6.3$ \\
\hline Mean cell volume (fL) & $66.3 \pm 1.6$ & $75.0 \pm 0.9$ \\
\hline Ferritin $(\mu \mathrm{g} / \mathrm{L})$ & $7.1 \pm 3.4$ & $17.0 \pm 3.3$ \\
\hline IDA detected at $12 \mathrm{mo}$, no. & 21 & 21 \\
\hline $\mathrm{Hb}(\mathrm{g} / \mathrm{L})$ & $102.2 \pm 1.4$ & $122.5 \pm 1.9$ \\
\hline $\begin{array}{l}\text { Erythrocyte protoporphyrin } \\
(\mu \mathrm{g} / \mathrm{dL} \text { RBC })\end{array}$ & $172.6 \pm 21.3$ & $80.1 \pm 3.8$ \\
\hline Mean cell volume (fL) & $65.9 \pm 0.9$ & $75.4 \pm 0.6$ \\
\hline Ferritin $(\mu \mathrm{g} / \mathrm{L})$ & $4.5 \pm 0.7$ & $19.0 \pm 2.5$ \\
\hline IDA detected at $18 \mathrm{mo}$, no. & 10 & 12 \\
\hline $\mathrm{Hb}(\mathrm{g} / \mathrm{L})$ & $106.7 \pm 1.0$ & $126.6 \pm 1.2$ \\
\hline $\begin{array}{l}\text { Erythrocyte protoporphyrin } \\
(\mu \mathrm{g} / \mathrm{dL} \mathrm{RBC})\end{array}$ & $144.4 \pm 9.7$ & $74.8 \pm 3.9$ \\
\hline Mean cell volume (fL) & $69.7 \pm 1.2$ & $76.3 \pm 0.9$ \\
\hline Ferritin $(\mu \mathrm{g} / \mathrm{L})$ & $7.7 \pm 1.1$ & $14.5 \pm 3.0$ \\
\hline
\end{tabular}

* Values are means \pm SE for continuous variables and percentages for categorical variables. Statistical significance was determined by $t$ test or chi square. RBC, red blood cells.

$\dagger p<0.10 ; \ddagger p<0.05$.

$\S$ By design, anemic and controls groups differed in hematologic status. All comparisons are statistically significant. 
significant relation to any ABR or VEP parameter and was omitted in final analyses. Hematologic status at the time of identification as IDA or control in infancy is also shown in Table 1. Oral iron therapy corrected anemia in all but one of these children; only five of the controls met biochemical criteria for iron deficiency at any time in infancy.

Procedures. All ABR and VEP measures were obtained and processed without knowledge of whether a given child was former IDA or control. The children were studied while awake during the daytime. Both ABR and VEP recordings were carried out in a quiet, dimly lit, and electrically shielded room using an integrated Nicolet Compact Four machine (Nicolet Biomedical Instruments, Madison, WI, U.S.A.). ABR and VEP were recorded using silver-silver chloride disk electrodes placed according to the 10-20 International System as follows: a) for $\mathrm{ABR}$, the active electrode was placed on the vertex $(\mathrm{Cz})$ and the reference one on the earlobe (A1 or A2) ipsilateral to the stimulation; a third electrode placed on the forehead was used as a ground; $b$ ) for VEP, electrodes were placed on the $\mathrm{Oz}$ (positive), FPz (negative), and $\mathrm{Cz}$ (common reference) positions. Interelectrode impedance was kept below 5 kiloohms.

Using the same procedures as in infancy, ABR were performed with the child in the supine position, elicited monaurally, stimulating the ipsilateral ear with a series of square wave rarefaction clicks $(0.1 \mathrm{~ms})$ through TDH-39 headphones at $85 \mathrm{~dB} \mathrm{nHL}$. The ABR were recorded twice to ensure reproducibility. Results were stored for off-line analyses. The following parameters were determined for every response: absolute latency and amplitude for waves I, III, and V, and interpeak latencies I-III, III-V, and I-V.

For VEP, children were seated alone in front of a monitor at a distance of $100 \mathrm{~cm}$ and were asked to look at a red point located at the center of the screen. Pattern stimuli (10 min of arc checks) were generated by a black and white video monitor. Checks were reversed at a rate of 1.9 alterations per second; the duration of the stimulus was $100 \mathrm{~ms}$ and acquisition time was $250 \mathrm{~ms}$. A total of 100 trials was obtained with automatic rejection of artifacts. The VEP were recorded at least twice to ensure reproducibility. The bioelectrical activity recorded at $\mathrm{Cz}$ was amplified, filtered (1 $\mathrm{Hz}$ to $100 \mathrm{kHz}$ ), and automatically averaged in the Nicolet $\mathrm{C} 4$ system. Results were stored for off-line analyses. The absolute amplitude and absolute latency for wave P100 were determined for each VEP response. Data on other waves were not recorded.

Statistical analysis. Analysis of covariance was used to determine differences between former IDA and control groups on continuous variables. Categorical variables were analyzed using $\chi^{2}$.

To address the issue of irregular progression versus developmental arrest, we used HLM (22), using mean CCT (wave I-V interval) data from the infant ABR study (8) to extrapolate the expected values if the rate of change remained the same. HLM estimates "growth" trajectories and allows determination of differences between groups in the parameters of the curves (e.g. base state, the linear change over time, the rate of change). In a two-level HLM analysis, level one provided parameters of change using an asymptotic model of decay. The asymptote was based on the observed mean CCT value of the nonanemic control group in the follow-up, and the value at birth was obtained from standard sources $(4,23)$. Level two of the model tested for significant differences in the change parameters between anemic and nonanemic groups, controlling for gestational age and birth weight. Gender was considered initially, but there were no significant differences $(p=0.38)$. HLM analyses were repeated using the values observed at $4 \mathrm{y}$ to revise the projections and predict the rate of change in the future.

The exploratory nature of the HLM analyses should be noted. There were no local norms for values at birth or adulthood, and only 13 ABR records were from children who had ABR in infancy (eight identified at 6 mo and five at 18 mo). Thus, the extrapolation depended on infancy data from children who could not be part of this follow-up because they were already over $4 \mathrm{y}$ of age. To consider the validity of the latter aspect, we first compared the ABR and VEP values for preschool-aged children with or without infancy data. There were no differences on any parameter.

\section{RESULTS}

Table 2 shows the mean and SEM for ABR and VEP, controlling for relevant background factors (age at testing, birth weight, gestational age, and gender). For ABR parameters, former IDA children had significantly longer latencies for all waves and all wave interpeak intervals except interval I-III. There were no differences in amplitude. For VEP, the latency of wave P100 was longer in former IDA compared with control children. Again, there was no difference in amplitude.

Figure 1 shows the magnitude of differences, expressed as effect sizes. Effect size is calculated as the difference between group means divided by the overall SD. Effect sizes for latencies were generally large to very large for ABR (about $0.8-1.2$ SD units) and very large for VEP (1.2 SD unit).

To determine whether differences between the former IDA and control groups varied depending on age at diagnosis of IDA in infancy, we repeated the analyses of covariance adding this factor. There were no significant main effects of age at diagnosis or interactions. Regardless of the age in infancy when IDA was detected, there were statistically significant differences between former IDA children and controls in the latencies of $\mathrm{ABR}$ waves I, III, and V and of wave P100. Differences in interwave intervals showed the same pattern at suggestive levels of statistical significance $(p \leq 0.10)$ with the added covariate.

In additional analyses of the ABR data to determine whether the more central or more distal components of the auditory pathway were differentially affected, we compared former IDA and control children on the central-to-peripheral ratio (wave III-V interval divided by wave I-III interval) (13), controlling for the background factors noted above. The central-toperipheral ratio was higher in former IDA children $(0.90 \pm$ 0.02 versus $0.83 \pm 0.02$ in controls, $\left.\mathrm{F}_{1,58}=7.01, p=0.01\right)$.

We also sought to determine how the observed values for CCT compared with those projected using HLM techniques (Fig. 2). From an estimated common starting point at birth, significant differences between IDA and control groups were 
Table 2. Evoked potentials*

\begin{tabular}{|c|c|c|c|}
\hline Group & Former IDA & Control & Significant background variables \\
\hline \multicolumn{4}{|c|}{ Auditory Brainstem Responses at $85 \mathrm{~dB}$} \\
\hline No. & 29 & 35 & \\
\hline \multicolumn{4}{|l|}{ Absolute latencies (ms) } \\
\hline Wave III $\dagger$ & $3.78 \pm 0.03$ & $3.63 \pm 0.02$ & \\
\hline Wave $\mathrm{V}^{\dagger}$ & $5.70 \pm 0.03$ & $5.40 \pm 0.03$ & Gestational age, testing age, gender \\
\hline \multicolumn{4}{|l|}{ Interpeak latencies (ms) } \\
\hline $\begin{array}{l}\text { Wave I-V interval (central } \\
\text { conduction time) } \dagger\end{array}$ & $4.06 \pm 0.03$ & $3.87 \pm 0.03$ & Gestational age, testing age, gender \\
\hline \multicolumn{4}{|l|}{ Amplitudes $(\mu \mathrm{V})$} \\
\hline Wave I & $0.57 \pm 0.04$ & $0.56 \pm 0.03$ & Birth weight \\
\hline Wave III & $0.51 \pm 0.03$ & $0.54 \pm 0.03$ & \\
\hline Wave V & $0.55 \pm 0.03$ & $0.57 \pm 0.03$ & Gender \\
\hline
\end{tabular}

* Values are adjusted means \pm SE, controlling for gender, birth weight, gestational age, weight gain from birth to 6 mo, and age at testing. Statistical significance was determined by analysis of covariance.

$\dagger p<0.001$.

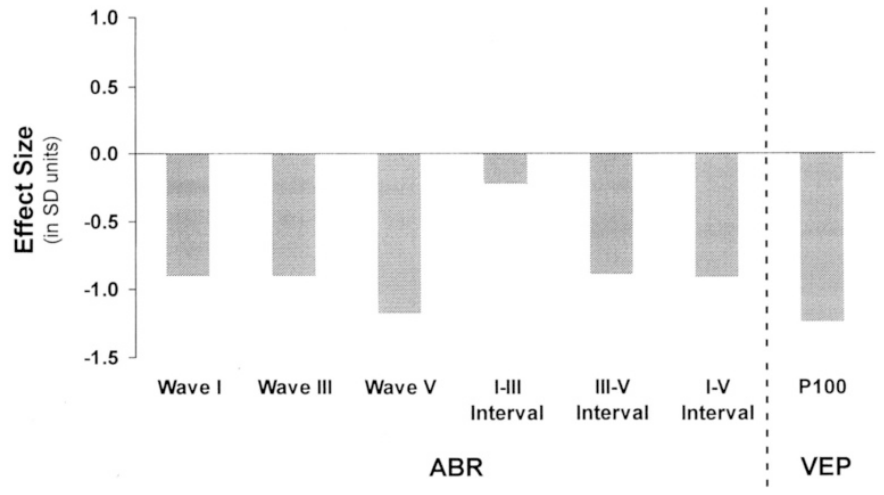

Figure 1. Magnitude of differences in evoked potential latencies between former IDA children and controls. Effect size is calculated as the control group mean minus the mean for former IDA children divided by the overall standard deviation. See Table 2 for levels of statistical significance.

observed in the amount of change by $6 \mathrm{mo}(p=0.02)$ and the rate of change over time $(p<0.01)$. These differences combine to project significantly different times for reaching the asymptotic level $(p<0.01)$. Based on the rate of change observed at the end of the infancy study, the projection indicated that the nonanemic control group reached the observed value of 3.86 $\mathrm{ms}$ before the follow-up, with virtually all change completed by 24 mo (Fig. 2, bottom curve). ABR maturation in the control group thus appeared to correspond to that published for normally developing children. Projecting the rate of change observed in infancy for the former IDA group, however, showed that the CCT expected at $4.3 \mathrm{y}$ (the average age at testing) was $3.89 \mathrm{~ms}$ (middle curve in Fig. 2). The value actually observed was $4.07 \mathrm{~ms}$ - a latency longer than predicted by approximately $1 \mathrm{SD}$. When HLM analyses were repeated using the additional observations from $4.3 \mathrm{y}$, the nonanemic trajectory changed little (and only one is graphed in Fig. 2). In contrast, the new projection for the former IDA group showed a drop significantly slower than that using the infancy data alone $(p<$

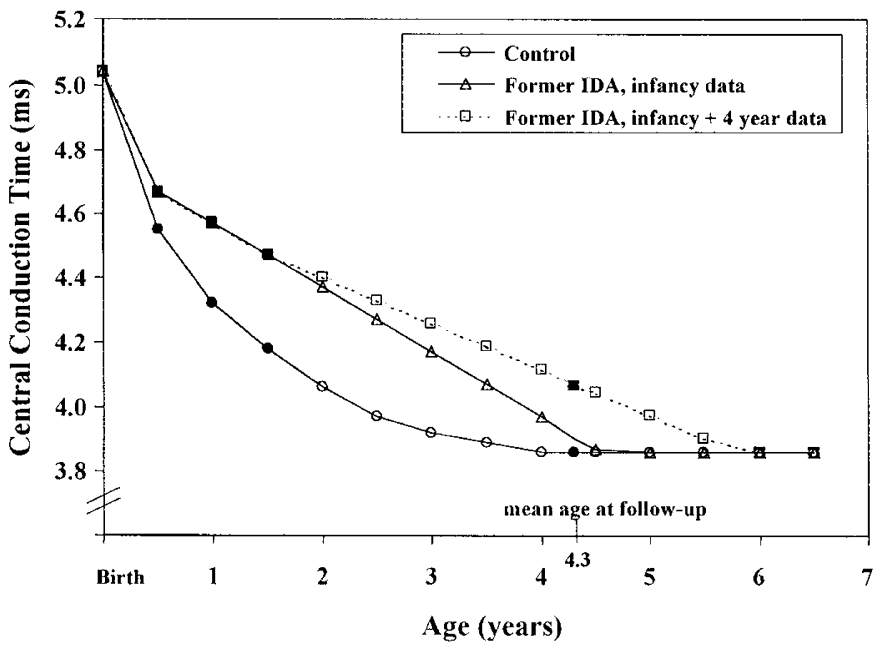

Figure 2. Projected rates of change in CCT. These curves are derived from HLM analyses. The bottom curve shows the pattern projected for the control group. The middle curve projects values for the former IDA group based on infancy data alone. The top curve shows the projection for former IDA children revised to include the observed value at 4.3 years. Points with solid black symbols are based on actual observations, and points with open symbols are estimated.

0.01 ) and predicted a much later time for achieving the asymptote $(p<0.01)$. The revised projection (uppermost curve in Fig. 2) predicts that former IDA children will not reach the level of the control group until approximately $6 \mathrm{y}$ of age.

\section{DISCUSSION}

The present study shows that ABR and VEP latencies were consistently longer in former IDA children relative to nonanemic controls, with differential effects on the more central portion of the auditory pathway. Differences in amplitudes were not statistically significant. Differences at follow-up were noted regardless of the age in infancy at which IDA had been 
detected and despite iron treatment that corrected anemia in infancy for all but one child. The magnitude of effects on latencies was generally large - approximately $1 \mathrm{SD}$, the same magnitude observed for ABR in infancy. These findings provide the first evidence that effects of IDA in infancy on pathway transmission in both the visual and auditory systems can be long lasting.

The formation of fully mature myelin is a process that takes months or even years $(24,25)$, and it is thus plausible that the effects of a developmental insult might be observed later on, even if the apparent cause were treated. Furthermore, a primary role of oligodendrocytes is myelin production, and oligodendrocytes depend on iron availability for normal function. During development, disruption in the availability of iron has been shown to impede myelination (26). These developmental features might help explain our findings, especially when considering the region-specific fashion of the temporal sequence of myelination during childhood and adolescence (25). Differences in latency but not in amplitude in former IDA children support the hypomyelination hypothesis. It is generally accepted that latency changes relate to increases in conduction velocity during axonal myelination (13-15), whereas modifications in amplitude and duration are probably the result of improvements in synchronization at the axonal or synaptic levels (27). However, we emphasize that this study did not directly demonstrate delayed myelination. Anatomic neuroimaging would be required for this purpose.

Other relevant human studies of IDA are scarce and provide little comparable information. In a previous study in China, ABR abnormalities were noted in $>50 \%$ of a group of 48 IDA infants (age range, 6 mo to $3 \mathrm{y}$ ); more severely anemic children had more severely disrupted ABR patterns (28). Reevaluation after iron therapy was performed only in four cases, with no clear pattern of results. In another study, in Turkey, ABR were also assessed in a group of infants averaging 14 mo of age (20 IDA, 20 controls), with repeat evaluations for the IDA group after 3 mo of iron therapy (29). No ABR differences between IDA and control infants were observed before treatment, but the expected developmental progression in ABR was not observed upon repeat assessment of IDA infants. Methodologic differences may account for the differences in findings between the Turkish study and our earlier ABR study. Infants in that study were evaluated under sedation, whereas our ABR assessments were performed without sedation during a spontaneously occurring nap. The age range was much wider (7-24 mo versus 6 mo in our study), and the time interval to reassessment was much shorter ( 3 mo versus 6 and 12 mo). The Turkish study also obtained VEP, but only in the IDA infants (again under sedation) before and after 3 mo (30). Without VEP in a control group, no pretreatment comparisons were possible. After $3 \mathrm{mo}$, the latency of a negative VEP component (N2) decreased, but it is not clear whether this change was the result of iron therapy or developmental progression. No study has evaluated longterm effects.

In animal models, there is evidence that early IDA effects on myelination are not reversed with iron therapy. In the developing rat with iron deficiency, cytological studies show that oligodendrocytes appear "immature" and do not revert to normal after treatment (31). An insult to the sensory receptor should also be considered. The only set of experimental studies of auditory functioning in developing rats found an auditory threshold elevation of $>15 \mathrm{~dB}$ in about one third of the animals with severe IDA (32) and sudden sensorineural hearing loss in a few (33). The effects were specific to iron deficiency rather than anemia. Despite these suggestive studies, the mechanisms for long-lasting IDA effects are still unknown. However, some studies have reported long-term effects on ABR in other early biologic risks, such as lead exposure $(34,35)$ and generalized undernutrition $(36,37)$, suggesting the fruitfulness of characterizing the underlying processes in a variety of insults or stressors to the developing brain.

The impact of early IDA on the functional maturation of the auditory system was still apparent in the present study despite an overall decrease in average latencies for most ABR parameters for both former IDA and control groups at preschool age. The HLM projections of CCT indicate that the control group probably followed the normal developmental time course. In contrast, developmental change in the former IDA group was slower than predicted by the rate of change observed at the end of the infancy study. Former IDA children had not achieved the level of maturity in CCT that would be expected, even if they simply maintained the course established in infancy. In fact, the revised projection incorporating the observed 4-y data (Fig. 2, top curve) indicates that the former IDA group will lag behind the control group for approximately another $2 \mathrm{y}$. The HLM results thus suggest that auditory transmission was slower in the former IDA group throughout early childhood.

Relation to broader differences in behavior and development. Differences in functioning of both the visual and auditory systems make it plausible that there might be a generalized impact of IDA on myelination. Impaired myelination may help explain differences in broader behavioral systems reported in other studies of iron deficiency in infancy (reviewed in ref. 38). Differences in motor development are certainly relevant in this context, as the direct and important role of myelination in early motor development is well established. Several studies have found lower motor test scores in IDA infants (see ref. 38). Of the few randomized trials of the behavioral and developmental effects of iron supplementation, those with assessments in the first year of life generally reported motor effects $(17,39,40)$.

Subtle alterations in auditory and visual processing could also contribute to specific cognitive outcomes reported in studies of early IDA (41). Longer ABR and VEP latencies might delay or disrupt the timing of input for other systems. In considering this line of reasoning, it should be recalled that altered myelination is not the only defect in early iron deficiency that might affect sensory processing. For instance, recent studies continue to document the alteration of dopaminergic functioning in iron deficiency (42). Dopamine neurotransmission has specific roles in circuits involved in transmitting visual and auditory information (43). In this context, altered dopaminergic function could disrupt the normal progression of fine-grained mechanisms of synchronization, including intermodal integration, inasmuch as connections might not be in place or fully functional at the expectable time (44). 
Delays in the maturational process or altered timing for achieving specific neurofunctional developmental patterns of the visual and auditory sensory systems could affect the development of higher-order cognitive and emotional functions. Adequate development and functional integrity of both auditory and visual systems are important in assuring the structural and functional foundations for many learning processes. We speculate that the above-mentioned factors contribute to behavioral and cognitive alterations that have been reported in former IDA children (45-47). Relevant mechanisms might include hypomyelination of both auditory and visual sensory pathways, alteration of neurotransmission systems, delayed and/or asynchronous maturation of the neural interactions among different sensory modalities, and decreased neuronal metabolic activity (48). These mechanisms might act directly, influencing brain structure, biochemistry, and functional development, or indirectly, modifying the neural integration that defines brain development. Moreover, these mechanisms are not mutually exclusive and might act synergistically to induce altered function.

We did not test whether the altered evoked potentials actually resulted in abnormal visual or auditory function. Further large-scale longitudinal studies are needed to reveal the clinical significance of the observed alterations in evoked potentials. However, the changes we noted could be relevant to some specific behavioral/developmental outcomes in other studies of early iron deficiency in the human. For instance, IDA infants showed evidence of slower processing of visual information (longer looking times). Looking time-considered a fundamental cognitive property reflecting efficiency of information processing $(49,50)$ - predicts later IQ better than global tests of infant development $(51,52)$. Two other studies found that 5to 51/2-y-old children who had had chronic, severe iron deficiency in infancy showed marked differences in visual-motor integration, perceptual speed, and/or motor proficiency (45, 46). In a follow-up at 11-14 y, such children showed poorer spatial memory and longer tachistoscopic threshold (the minimum time to perceive a difference in stimuli) and did not display the expected developmental shift in selective recall (47). Such findings appear compatible with disruptions in sensory processing and/or intermodal integration.

Limitations. It should be emphasized that our consideration of ABR results at preschool age in relation to patterns in infancy relies on group means only, because there were longitudinal data for only 13 children. Nonetheless, finding no differences on any ABR or VEP parameter among preschoolaged children who did or did not have infancy data suggests that those in the infant study were not atypical and that the rest of the sample can be considered a quasi-replication or internal confirmation of the results for children with longitudinal observations. However, the fact that we did not observe an effect of age at diagnosis of IDA does not mean that timing is unimportant. Our data only encompass the relatively narrow window of $6-18 \mathrm{mo}$. This period is largely after the exponential phase of ABR and VEP maturation. IDA occurring earlier (during the period of exponential change) or later (after maturation is largely complete) might well have different effects. Therefore, according to the timing of myelination and synap- togenesis within sensory pathways, one might expect greater ABR or VEP alterations in infants diagnosed as IDA at 6 mo of age. However, it is also conceivable that plasticity and recovery might be more possible earlier on.

\section{CONCLUSION}

In conclusion, IDA during infancy seems to induce mild auditory and visual dysfunctions that are long lasting. We suggest that these insults may act synergistically to disrupt the timing of key steps in CNS development, thus derailing the normal progression of neurofunctional maturation. Sustained during early development, these functional effects may limit the benefits conferred by environmental stimulation and contribute to long-lasting alterations in cognition and behavior among former IDA children.

Acknowledgments. The authors thank the children and parents who participated in this study for their cooperation. We also thank Miriam Dinamarca for valuable technical assistance, Julia B. Smith for HLM analyses and other statistical assistance, and Héctor Pedreros for providing careful transportation services to children and parents. We thank the Nestlé Foundation for support during the initial steps of the research program at the Laboratory of Sleep and Functional Neurobiology, INTA, University of Chile.

\section{REFERENCES}

1. Jewett DL, Romano MN, Williston JS 1970 Human auditory evoked potentials: possible brainstem components detected on the scalp. Science 167:1517-1518

2. Jewett DL, Williston JS 1970 Auditory evoked far fields averaged from the scalp in humans. Brain 94:681-696

3. Moller AR, Janetta PJ 1982 Evoked potentials from the inferior colliculus in man. Electroencephalogr Clin Neurophysiol 53:612-620

4. Mochizuki Y, Go T, Ohkubo H, Tatara T, Motomura T 1982 Developmental changes of brainstem auditory evoked potentials (BAEPs) in normal human subjects from infants to young adults. Brain Dev 4:127-136

5. Tsuneishi S, Casaer P 1997 Stepwise decrease in VEP latencies and the process of myelination in the human visual pathway. Brain Dev 19:547-551

6. Moller AR, Janetta PJ, Moller MB 1981 Neural generators of brainstem evoked potentials: results from human intracranial recordings. Ann Otol Rhinol Laryngol 90:591-596

7. Moore JK, Linthicum FHJ 2001 Myelination of the human auditory nerve: different time courses for Schwann cell and glial myelin. Ann Otol Rhinol Laryngol 110:655661

8. Roncagliolo M, Garrido M, Walter T, Peirano P, Lozoff B 1998 Evidence of altered central nervous system development in infants with iron deficiency anemia at $6 \mathrm{mo}$ delayed maturation of auditory brain stem responses. Am J Clin Nutr 68:683-690

9. Larkin EC, Rao GA 1990 Importance of fetal and neonatal iron: adequacy for normal development of central nervous system. In: Dobbing J (ed) Brain, Behaviour, and Iron in the Infant Diet. Springer-Verlag, London, pp 43-62

10. Connor JR, Benkovic SA 1992 Iron regulation in the brain: histochemical, biochemical, and molecular considerations. Ann Neurol 32:S51-S61

11. Connor JR, Menzies SL 1990 Altered cellular distribution of iron in the central nervous system of myelin deficient rats. Neuroscience 34:265-271

12. Yu GS, Steinkirchner TM, Rao GA, Larkin EC 1986 Effect of prenatal iron deficiency on myelination in rat pups. Am J Pathol 125:620-624

13. Jiang ZD 1995 Maturation of the auditory brainstem in low risk-preterm infants: comparison with age-matched full term infants up to 6 years. Early Hum Dev 42:49-65

14. Salamy A, McKean CM 1976 Post-natal development of human brainstem potentials during the first year of life. Electroencephalogr Clin Neurophysiol 40:418-426

15. Hecox K, Burkard R 1982 Developmental dependencies of the human brainstem auditory evoked response. Ann N Y Acad Sci 388:538-556

16. Russo FDI, Martinez A, Sereno MI, Pitzalis S, Hillyard SA 2001 Cortical sources of the early components of the visual evoked potential. Hum Brain Mapping 15:95-111

17. Lozoff B, De Andraca I, Castillo M, Walter T, Smith J, Pino P 2001 Behavioral and developmental benefits of preventing iron deficiency anemia in healthy full-term infants. Pediatr Res 49:24A

18. Dallman PR, Reeves JD, Driggers DA, Lo EYT 1981 Diagnosis of iron deficiency: the limitations of laboratory tests in predicting response to iron treatment in 1-yearold infants. J Pediatr 98:376-381 
19. Nathan DG, Orkin SH 1998 Hematology of Infancy and Childhood, 5th Ed. WB Saunders, Philadelphia

20. Dallman PR, Siimes MA 1979 Percentile curves for hemoglobin and red cell volume in infancy and childhood. J Pediatr 94:26-31

21. Deinard AS, Schwartz S, Yip R 1983 Developmental changes in serum ferritin and erythrocyte protoporphyrin in normal (nonanemic) children. Am J Clin Nutr 38:71-75

22. Bryk A, Raudenbush SW 1992 Hierarchical Linear Models: Applications and Data Analysis Methods. Sage Publications, Newbury Park, CA

23. Eggermont JJ, Salamy A 1988 Maturational time course for the ABR in preterm and full term infants. Hearing Res 33:35-47

24. Kos-Pietro S, Towle VL, Cakmur R, Spire JP 1997 Maturation of human visual evoked potentials: 27 weeks conceptional age to 2 years. Neuropediatrics 28:318-323

25. Paus T, Collins DL, Evans AC, Leonard G, Pike B, Zijdenbos A 2001 Maturation of white matter in the human brain: review of magnetic resonance studies. Brain Res Bull 54:255-266

26. Connor JR, Menzies SL 1996 Relationship of iron to oligodendrocytes and myelination. GLIA 17:83-93

27. Rudell AP 1987 A fiber tract model of auditory brain-stem responses. Electroencephalogr Clin Neurophysiol 67:53-62

28. Li YY, Wang HM, Wang WG 1994 The effect of iron deficiency anemia on the auditory brainstem response in infant. Natl Med J China 74:367-369

29. Sarici SU, Serdar MA, Dundaroz MR, Unay B, Akin R, Deda G, Gokcay E 2001 Brainstem auditory-evoked potentials in iron-deficiency anemia. Pediatr Neurol 24:205-208

30. Sarici SU, Okutan V, Dundaroz MR, Serdar AM, Akin R, Deda G, Gokcay E 2001 The effect of iron supplementation on visual-evoked potentials in infants with iron deficiency anemia. J Trop Pediatr 47:132-135

31. Erikson K, Pinero DJ, Connor JR, Beard JL 1997 Regional brain iron, ferritin and transferrin concentrations during iron deficiency and iron repletion in developing rats. J Nutr 127:2030-2038

32. Sun AH, Xiao SZ, Li BS, Li ZJ, Wang TY, Zhang YS 1987 Iron deficiency and hearing loss. Experimental study in growing rats. ORL J Otorhinolaryngol Relat Spec 49:118-122

33. Sun AH, Wang ZM, Xiao SZ, Li ZJ, Zheng Z, Li JY 1992 Sudden sensorineural hearing loss induced by experimental iron deficiency in rats. ORL J Otorhinolaryngol Relat Spec 54:246-250

34. Lilienthal H, Winneke G 1996 Lead effects on the brain stem auditory evoked potential in monkeys during and after the treatment phase. Neurotoxicol Teratol 18:17-32

35. Lasky RE, Maier MM, Snodgrass EB, Hecox KE, Laughlin NK 1995 The effects of lead on otoacoustic emissions and auditory evoked potentials in monkeys. Neurotoxicol Teratol 17:633-644

36. Barnet AB, Weiss IP, Sotillo MV, Ohlrich ES, Shkurovich M, Cravioto J 1978 Abnormal auditory evoked potentials in early infancy malnutrition. Science 201:450
37. Bartel PR, Robinson E, Conradie JM, Prinsloo JG 1986 Brainstem auditory evoked potentials in severely malnourished children with kwashiorkor. Neuropediatrics $17: 178-182$

38. Grantham-McGregor S, Ani C 2001 A review of studies on the effect of iron deficiency on cognitive development in children. J Nutr 131:649S-668S

39. Moffatt MEK, Longstaffe S, Besant J, Dureski C 1994 Prevention of iron deficiency and psychomotor decline in high risk infants through iron fortified infant formula: randomized clinical trial. J Pediatr 125:527-534

40. Jahari AB, Saco-Pollitt C, Husaini M, Pollitt E 2000 Effects of energy and micronutrient supplementation on motor development and motor activity in undernourished children in Indonesia. Eur J Clin Nutr 54:S60-S68

41. Peirano P, Algarin C, Garrido L, Pizarro F, Roncagliolo M, Lozoff B 2001 Interaction of iron deficiency anemia (IDA) and neurofunctions in cognitive development. In: Fernstrom JD, Uauy R, Arroyo P (eds) Nutrition and Brain. Karger, Basel, pp 19-39

42. Nelson CA, Erikson K, Pinero DJ, Beard JL 1997 In vivo dopamine metabolism is altered in iron-deficient anemic rats. J Nutr 127:2282-2288

43. Antal A, Keri S, Bodis-Wollner J 1997 Dopamine D2 receptor blockade alters the primary and cognitive components of visual evoked potentials in the monkey, Maccaca fascicularis. Neurosci Lett 232:179-181

44. Wallace MT, Wilkinson LK, Stein B 1996 Representation and integration of multiple sensory inputs in primate superior colliculus. J Neurophysiol 76:1246-1266

45. Lozoff B, Jimenez E, Wolf AW 1991 Long-term developmental outcome of infants with iron deficiency. N Engl J Med 325:687-694

46. De Andraca I, Walter T, Castillo M, Pino P, Rivera P, Cobo C 1991 Iron deficiency anemia and its effects upon psychological development at preschool age: a longitudinal study. Nestle Foundation Nutrition Annual Report 1990. Nestec Ltd., Vevey, Switzerland, pp 53-62

47. Lozoff B, Jimenez E, Hagen J, Mollen E, Wolf AW 2000 Poorer behavioral and developmental outcome more than 10 years after treatment for iron deficiency in infancy. Pediatrics e51:1-11

48. DeUngria M, Rao R, Wobken JD, Luciana M, Nelson CA, Georgieff MK 2000 Perinatal iron deficiency decreases cytochrome c oxidase (CytOx) activity in selected regions of neonatal rat brain. Pediatr Res 48:169-176

49. Detterman DK 1987 What does reaction time tell us about intelligence? In: Vernon PA (ed) Speed of Information-Processing and Intelligence. Ablex, Norwood, NJ, pp 177-200

50. Kail R 1992 Processing speed, speech rate, and memory. Dev Psychol 28:899-904

51. Colombo J, Mitchell DW 1990 Individual differences in early visual attention: fixation time and information processing. In: Colombo J, Fagen J (eds) Individual Differences in Infancy: Reliability, Stability, Prediction. Erlbaum, Hillsdale, NJ, pp 193-227

52. Jacobson SW, Chiodo LM, Jacobson JL 1996 Predictive validity of infant recognition memory and processing speed to 7-year IQ in an inner-city sample. Inf Behav Dev $19: 524$ 